\title{
Effect of High-Temperature Quenching on the Phase Composition, Structure, and Wear Resistance of Ni-Hard Chromium-Nickel Cast Iron
}

\author{
M.A. Filippov ${ }^{1, *}$, V.A. Sharapova ${ }^{1}$, L.A. Moshechkova ${ }^{1}$, and S.O. Morozov ${ }^{1}$ \\ ${ }^{1}$ Ural Federal University (UrFU), 620002 Ekaterinburg, 19 Mira st., Russia
}

\begin{abstract}
Metallographic, micro-X-ray spectral and X-ray structural analyses have been carried out. The quenching temperature increase from 900 to $1150{ }^{\circ} \mathrm{C}$ leads to high abrasive wear resistance in Ni-hard chromium-nickel cast iron. The initial hardness decreased before the test from 60 to $35 \mathrm{HRC}$ due to the fact that the phase composition of the metal base before the wear test changes during quenching from medium-carbon martensite with secondary cementite to retained metastable austenite. It contributes to increase the crack resistance of cast iron. Austenite turns into dispersed friction martensite on the working surface in the process of wear testing or operation, as a result of the impact of abrasive particles. This martensite together with a part of cementite provides a high level of hardening and operability of the cast iron secondary microstructure.
\end{abstract}

\section{Introduction}

Wear-resistant chromium cast iron (WCCI) serves as a material that provides high operational resistance of parts that work mainly in conditions of abrasive wear [1,2]. This quality is ensured in the WCCI by the combination of a significant amount of solid carbides (doped cementite and special carbides), up to $50 \%$, and a favorable metal base, which must be sufficiently strong and well fix the carbide particles. The metal base (matrix) of the WCCI is made up of austenite and its transformation products. To the greatest extent, martensite and metastable retained austenite meet the requirements for wear-resistant chromium cast irons [2-5].

The most common representatives of cast irons of this class are low-alloyed, or ledeburite (with eutectic based on alloyed cementite $\mathrm{M}_{3} \mathrm{C}$ ) Ni-hard class cast irons, alloyed with nickel and chromium (in a ratio of $2.0 \div 2.5$ to 1 ) in order to obtain carbides harder than cementite. High-carbon (standard) Ni-hard cast iron $(3.0 \div 3.6 \% \mathrm{C}, 0.4 \div 0.7 \% \mathrm{Si}, 0.4 \div 0.7 \%$ $\mathrm{Mn} ; 1.4 \div 2.5 \% \mathrm{Cr}, 3.4 \div 4.75 \% \mathrm{Ni}$ ) has a hardness of approximately $550 \mathrm{HB}$ and is used for parts operating under conditions of intense wear at moderate impact loads and at operating temperatures up to $400{ }^{\circ} \mathrm{C}$ : balls and linings of ball mills, roll heads of mills for fine grinding of coal, pipeline elbows in pneumatic sand transport, parts of runners and

\footnotetext{
*Corresponding author: filma1936@mail.ru
} 
sandblowers The disadvantage of the standard Ni-hard is low impact resistance and lower wear resistance compared to high-chromium cast irons $(13-28 \% \mathrm{Cr}$ ), which have special carbides $\mathrm{M}_{7} \mathrm{C}_{3}$ and $\mathrm{M}_{23} \mathrm{C}_{6}$.

It was previously shown that the application of high-temperature quenching up to 1170 ${ }^{\circ} \mathrm{C}$ to cast irons $250 \mathrm{Kh} 16 \mathrm{M} 2$ and $250 \mathrm{Kh} 25 \mathrm{MFT}$ with special carbides $\mathrm{M}_{7} \mathrm{C}_{3}$ and $\mathrm{M}_{23} \mathrm{C}_{6}$ allows them to form a metal base with the structure of metastable austenite and a corresponding increase in abrasive wear resistance by about $20 \%$ [1,2]. It is of scientific and practical interest to study the possibility of increasing the abrasive wear resistance of economically alloyed Ni-hard cast irons by increasing the quenching temperature to obtain retained austenite on the working surface with the formation of strain martensite during operation in terms of achieving high wear resistance. Therefore, it is advisable to develop a technological mode of heat treatment of the studied cast iron, which provides the necessary phase composition of the metal base, which contains a controlled amount of carbides, martensite and metastable austenite.

\section{Material and methodology of the study}

For the study, samples of white rolled chromium-nickel cast iron of the Ni-hard class melted in an induction furnace. The chemical composition is given in Table 1.

Table 1. Chemical composition of cast iron (\%by weight)

\begin{tabular}{|c|c|c|c|c|c|c|}
\hline $\mathrm{C}$ & $\mathrm{Cr}$ & $\mathrm{Ni}$ & $\mathrm{Si}$ & $\mathrm{Mn}$ & $\mathrm{S}$ & $\mathrm{P}$ \\
\hline 3.12 & 2.11 & 4.26 & 0.65 & 0.60 & 0.035 & 0.042 \\
\hline
\end{tabular}

Comparative tests of the abrasive wear resistance of samples measuring $11 \times 11 \mathrm{~mm}$ were carried out in a quenched state after heating in a wide temperature range of 850-1150 ${ }^{\circ} \mathrm{C}$ and cooling in oil. The upper range of the quenching temperature is limited due to the lower eutectic transformation temperature compared to high-chromium cast irons. The exposure time at the heating temperature was 20 minutes. The wear resistance was evaluated according to the method of wear on the fixed abrasive, implemented on a special installation based on a planer machine. Samples with an area of the working part of $10 \times 10$ $\mathrm{mm}$ made a reciprocating motion on the sanding paper 14A32MN481 (GOST 6456-82) on a corundum basis. The length of one working stroke of the samples was $0,125 \mathrm{~m}$, the friction path of the sample for one test at a speed of $0,158 \mathrm{~m} / \mathrm{sec}$. was $30 \mathrm{~m}$. The normal load acting on the sample is $10 \mathrm{~N}$ (specific load of $1 \mathrm{MPa}$ ). The value of the transverse displacement of the sanding paper for one double stroke of the sample was $1.2 \mathrm{~mm}$. The abrasive wear resistance was determined by the results of two parallel tests (the reference is samples of U7 rail steel made from massive samples after cooling from $820^{\circ} \mathrm{C}$ in oil with a sorbitol structure and a hardness of $37 \mathrm{HRC}$ ), the results were compared in relative units:

$\varepsilon-$ relative wear resistance,

$$
\varepsilon=\frac{\Delta \mathrm{M}_{\ni}}{\Delta \mathrm{M}_{\mathrm{o}}}
$$

$\Delta \mathrm{M}_{\ni}$ - the mass loss of the reference sample (U7 rail steel with a quenching sorbitol structure, hardness $37 \mathrm{HRC}$ ) was $0.5 \mathrm{~g}$.,

$\Delta \mathrm{M}_{\mathrm{o}}-$ mass loss of the test sample.

The test results are given as the average weight loss of the samples for the two tests. 


\section{Results and discussion}

As a result of an increase in the quenching temperature from 850 to $1150{ }^{\circ} \mathrm{C}$ the microstructure of cast iron externally changes little - the amount of ledeburite is about $30 \%$ (Fig. 1).

Changes occur mainly in the structure of the metal base, in the phase composition of which is initially insignificant, and, starting from the quenching temperature of $900{ }^{\circ} \mathrm{C}$, the amount of retained austenite progressively increases (Fig.2).

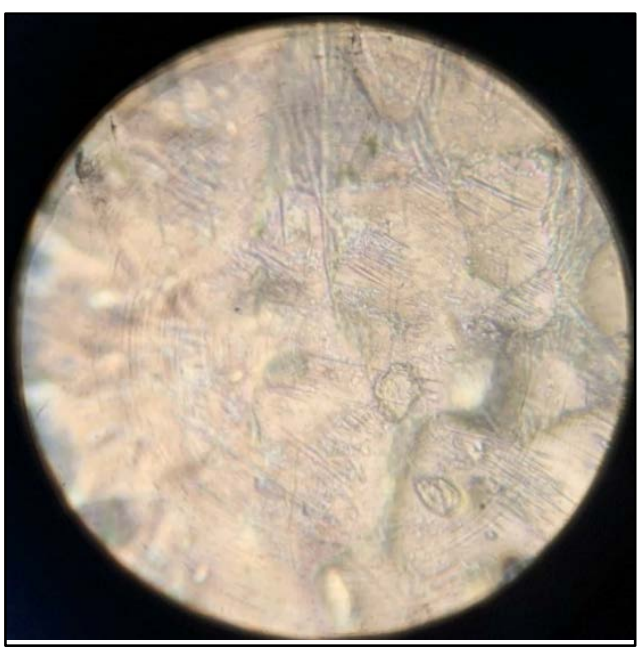

a

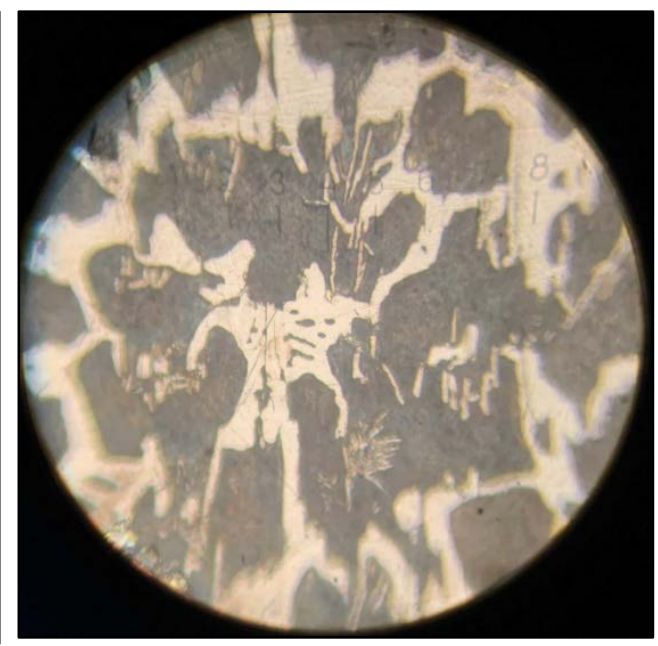

b

Fig. 1. Microstructure of cast iron after quenching from $850^{\circ} \mathrm{C}(\mathrm{a})$ and $1150{ }^{\circ} \mathrm{C}(\mathrm{b}), \mathrm{x} 200$

The results of the influence of the quenching temperature on the hardness, the phase composition of the metal base before and after testing the test samples for abrasive wear of the test cast iron in comparison with steel U7, as well as the microhardness of the working surface of the samples $\left(\mathrm{HV}_{50}\right)$ are shown in Fig. 2-4.

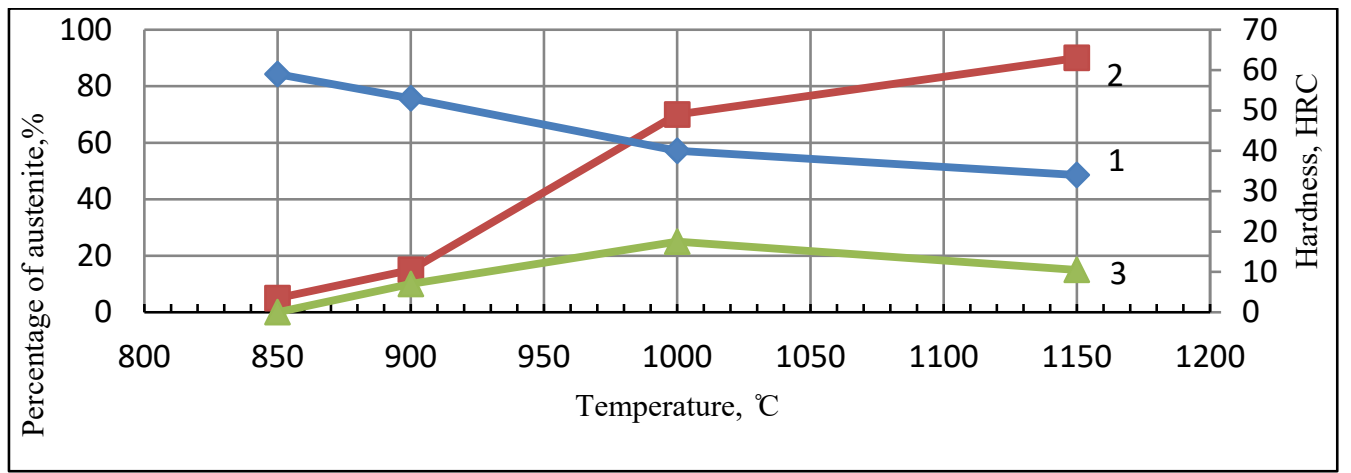

Fig. 2. Dependence of the hardness (1) and the amount of retained austenite before (2) and after (3) wear on the working surface of cast iron on the quenching temperature 


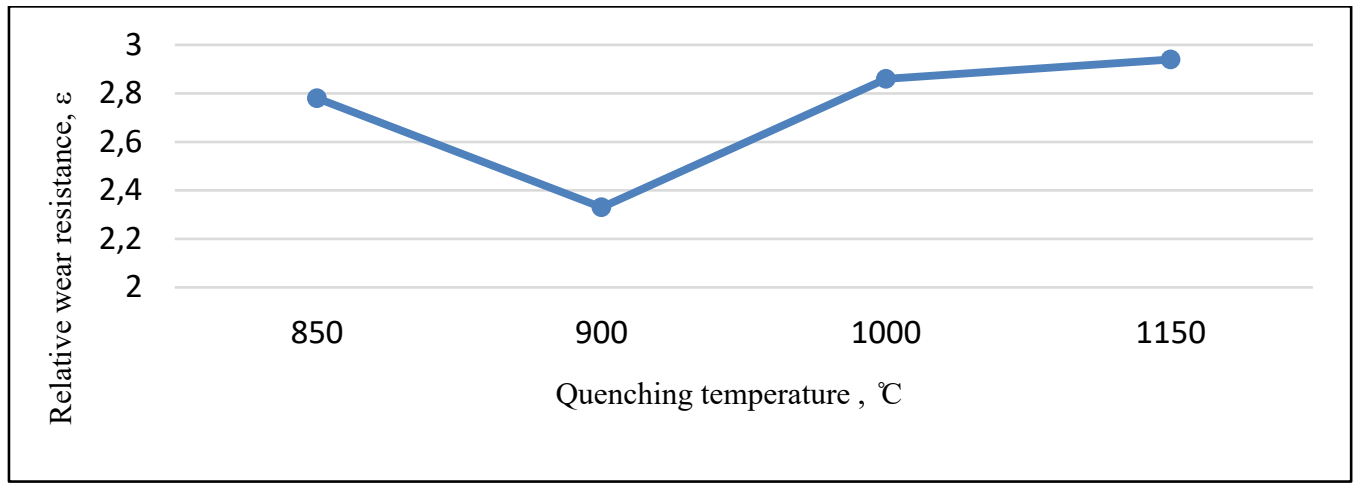

Fig. 3. Dependence of the relative wear resistance of cast iron on the quenching temperature

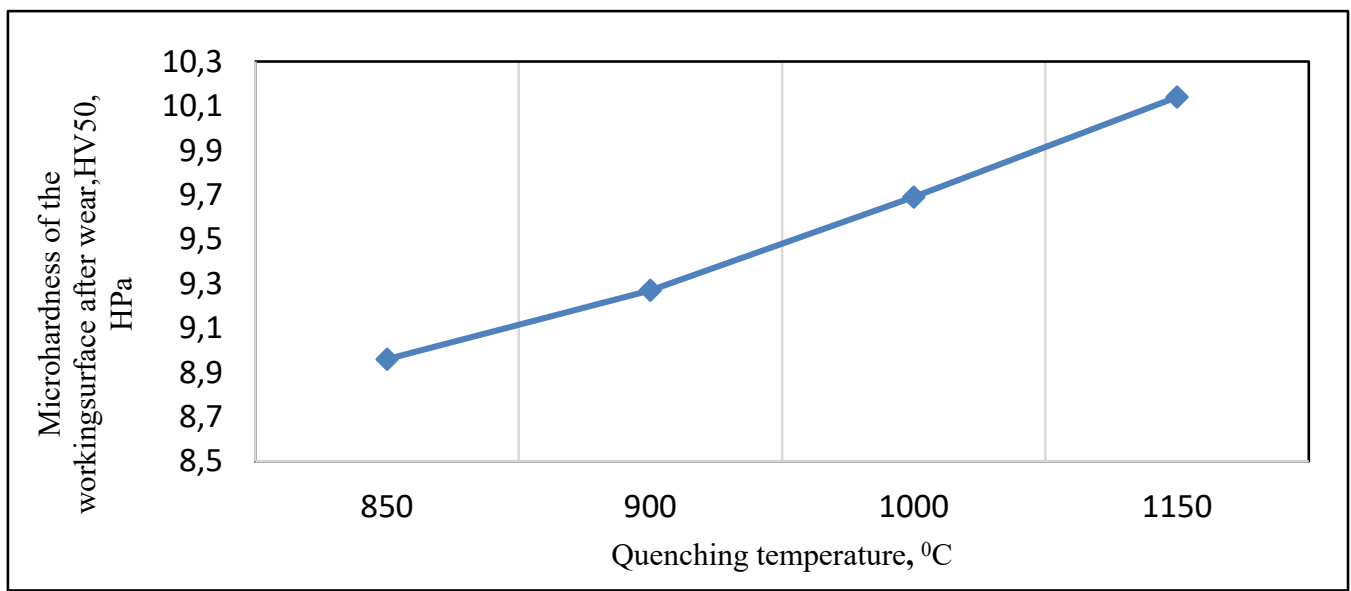

Fig. 4. Dependence of the microhardness of the working surface after wear on the quenching temperature

From the data in Fig. 2 it can be seen that for the Ni-hard 300Kh2N4 cast iron studied in this work, depending on the quenching temperature, the hardness naturally decreases from 60 to $35 \mathrm{HRC}$ in the studied temperature range due to the gradual saturation of austenite with carbon and alloying elements and a significant increase in the amount of retained austenite and the volume of strain martensitic transformation (SMT) during the test itself, which causes an increase in the effective microhardness (the degree of hardening of the working surface) during wear (Fig. 4). Regardless of the quenching temperature, one type of carbides was identified - doped cementite, $(\mathrm{Fe}, \mathrm{Cr}){ }_{3} \mathrm{C}$.

A good correlation between the maximum values of relative wear resistance and effective microhardness, starting from the quenching temperature of $900{ }^{\circ} \mathrm{C}$, can be judged from the comparison of the data in Fig. 3 and 4. The higher the microhardness of the secondary structure formed on the working surface, the thinner the metal layer is involved in creating the working layer that provides energy dissipation of abrasive particles, the less deep the layer is the separation of wear particles, hence the higher the abrasive wear resistance.

It is characteristic that the chemical composition of the metal base of the alloys should have a carbon content of $0.5-0.7 \%$ and a corresponding combination of chromium, manganese and other alloying elements to ensure the metastability of austenite, $-196{ }^{\circ} \mathrm{C}<$ $\mathrm{M}_{\mathrm{s}}, \mathrm{M}_{\mathrm{d}}>20^{\circ} \mathrm{C}[2,3]$. When the carbon content is less than $0.5 \%$, a high level of hardening is not achieved due to the formation of strain martensite, and when the carbon concentration 
exceeds $0.7 \%$, austenite becomes too stable with respect to the strain martensite transformation [3]. From the standpoint of the synergetic approach to open systems, metastable austenite has the most properties of dynamic structures - adaptation, selfreproduction, variability, selection of the most stable structure, and the ability to strengthening [5].

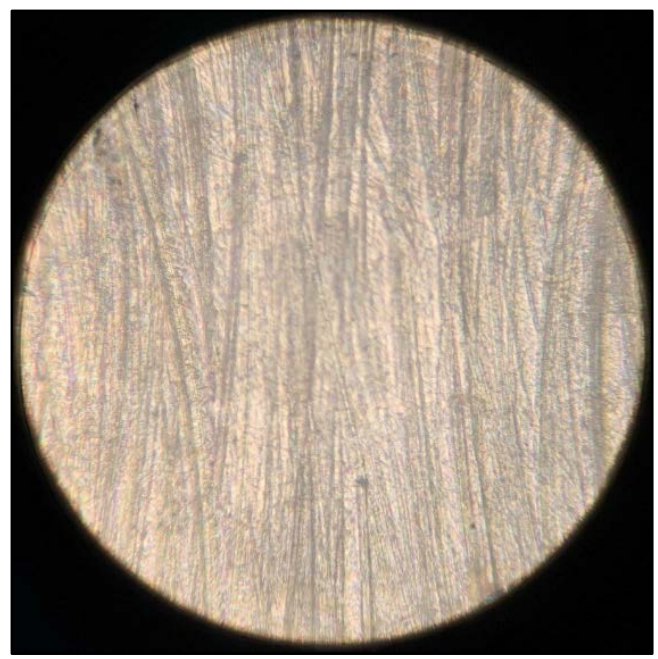

Fig. 5. Microstructure of the working surface after wear after quenching from $1000{ }^{\circ} \mathrm{C},{ }^{\mathrm{x}} 200$

Dispersed strain martensite crystals with the length of the long axis, apparently corresponding to the width of the micro-scratches left after the passage of abrasive particles, are formed in parallel periodic rows. The size of strain martensite crystals refers to dispersed values and is mainly 10-12 microns in local areas of the surface. Strain martensite crystals formed in the longitudinal and transverse directions, at angles determined by the crystallographic relations of the austenite lattice with respect to the direction of movement of the particles. Apparently, such a wave character of the arrangement of strain martensite crystals in the form of parallel rows is due to the formation of alternating peaks of compressive stresses at the front of moving abrasive particles and tensile stresses after the passage of the particle in this micro-volume of the metal (Fig. 5). Martensite crystals with a large specific volume in comparison with austenite are formed in those areas of austenite where the peak tensile stresses exceed the critical shear value during the martensite transformation. The formation of strain martensite crystals is accompanied by a micro-TRIP effect [6]. Since the microstructure presented in Fig. 5 is obtained from a single grain of austenite under a steady state of friction, the arrangement of martensite crystals with regular parallel rows in different micro-scratches on the surface of the samples can be explained by the action of a uniform stress field with the same orientation of the austenite crystal lattice. Reinforcement of the working surface with dispersed martensite crystals, which stimulate the micro-TRIP effect and relaxation of micro-stresses at the moment of shear, makes it difficult to introduce abrasive particles, increasing wear resistance.

\section{Conclusion}

An increase in the heating temperature for quenching low-alloy Ni-hard cast iron, $300 \mathrm{Kh} 2 \mathrm{~N} 4$, from 850 to $1150{ }^{\circ} \mathrm{C}$ causes, as in high-chromium cast irons, a progressive 
decrease in hardness from 59 to 35 HRC. This decrease in hardness occurs more intensively than in high-chromium cast irons, due to the lower activation energy of dissolution of alloyed cementite $\mathrm{M}_{3} \mathrm{C}$ when heated to lower temperatures than special carbides $\mathrm{M}_{7} \mathrm{C}_{3}$ and $\mathrm{M}_{23} \mathrm{C}_{6}$ in high-chromium cast irons, and the formation of up to $90 \%$ of the retained austenite in the initial state before the test.

The decrease in the initial hardness of Ni-hard cast iron after high-temperature quenching does not cause a decrease in its abrasive wear resistance, and starting from the quenching temperature of $1000{ }^{\circ} \mathrm{C}$, on the contrary, increases in the same way as it occurs in high-chromium cast irons, but with a lower intensity, by $10-15 \%$.

This "high-temperature quenching effect" is due to the metastability of the retained austenite and its transformation into fine-crystalline strain martensite on the wear surface with the creation of an increased level of friction hardening of the working surface.

Authors are grateful for the participation of V.P. Shveykin and S.Kh. Estemirova.

\section{References}

1. V.I. Kulikov, Alloyed cast iron. Mechanical engineering. Encyclopedia (Mashinostroenie, Moscow, 2001)

2. M.A. Filippov, V.A. Sharapova, V.P. Shveykin, Liteyschik Rossii, 8, 35-40 (2020)

3. M.A. Filippov, P. Lhagvadorj, G.N Plotnikov, MiTOM, 4, 7-10 (1996)

4. O.S. Komarov, V.M. Sadovsky, V.I. Urbanovich, S.V. Grigoriev, MiTOM, 7, 20-23 (2003)

5. V.S. Ivanova, MiTOM, 2, 12-19 (2005)

6. M.L. Bernstein, V.A. Zaymovsky, P.M Kaputkina, Thermomechanical processing of steel (Metallurgy, Moscow, 1983) 